\title{
OBSERVAȚII DESPRE RĂZBOIUL DE A CINCEA GENERAȚIE ŞI CEL DE-AL DOILEA RĂZBOI DIN NAGORNO-KARABAKH
}

\author{
REMARKS ON THE FIFTH-GENERATION WARFARE \\ AND THE SECOND NAGORNO-KARABAKH WAR
}

\author{
Conf.univ.dr. Alba-Iulia Catrinel POPESCU*
}

Cel de-al doilea război din Nagorno-Karabakh, din toamna anului 2020, este considerat a fi un punct de inflexiune în privinţa modului de purtare a războiului. Dacă, până atunci, războiul de a cincea generaţie reprezenta doar un subiect teoretic, iar doctrina tradiţională care susţinea că superioritatea aeriană este o condiţie prealabilă pentru câștigarea unui război terestru devenise obiect de studiu al istoricilor militari, cea mai recentă exacerbare a conflictului armeano-azer din Transcaucazia a schimbat radical situaţia. Războiul de a cincea generaţie, dominat de acțiuni noncinetice, în defavoarea celor cinetice, de înalte tehnologii, în defavoarea mijloacelor clasice, convenţionale, este cât se poate de real, iar teoria puterii aeriene revine în forţă. Articolul de faţă îşi propune să răspundă la următoarele întrebări: Care sunt caracteristicile războiului de a cincea generaţie? Cum s-au manifestat ele în cel de-al doilea război din Nagorno-Karabakh? Care a fost impactul confruntării militare din Transcaucazia asupra modului de ducere a războiului modern?

The second Nagorno-Karabakh War in the autumn of 2020 is considered a turning point in the conduct of warfare. Until then, the fifth-generation warfare was only a theoretical subject. Also, the traditional air-power doctrine, claiming that air superiority is a precondition for winning a ground war, had become a topic for military historians. Yet, the latest exacerbation of the Armenian-Azerbaijani conflict in Transcaucasia radically changed the situation. The fifth-generation warfare, dominated by non-kinetic actions to the detriment of the kinetic ones and by high technologies to the detriment of the classical, conventional ones, is as real as possible and the theory of air power returns in force. This article aims to answer the following questions: what are the characteristics of the fifth-generation warfare and how did they manifest in the Second Nagorno-Karabakh War? And what was the impact of the military confrontation in Transcaucasia on the way modern warfare was conducted?

Cuvinte-cheie: războiul de a cincea generaţie; Nagorno-Karabakh; rețele digitale; combat cloud; sistemele aeriene fără pilot.

Keywords: the fifth-generation warfare; Nagorno-Karabakh; digital networks; cloud combat; unmanned aerial systems.

\section{Despre războiul de a cincea generație}

Criteriul „generaţional” în istoria războiului a fost introdus relativ recent. O echipă de analiști politico-militari americani, în frunte cu William S. Lind, a structurat „faţa schimbătoare a războiului”, pornind de la o serie de indicatori privind mărimea armatelor, natura echipamentelor militare, tacticile folosite în ducerea războiului ${ }^{1}$. Astfel, afirmau ei, în 1989, în mileniile scurse din Antichitate până în contemporaneitate, războiul a cunoscut doar patru generaţii, dintre care ultimele două s-au dezvoltat în a doua jumătate a secolului al XX-lea, în paralel cu

\section{*Universitatea Națională de Apărare „Carol I e-mail:albapopescu1@gmail.com}

avansul tehnologic şi cu noile revoluţii industriale ale computerizării şi digitizării. Sau, altfel spus, modul în care a fost făcut războiul a reflectat modul în care a fost făcută bogăția ${ }^{2}$. Secolul vitezei şi-a pus amprenta şi asupra războiului, poate cel mai conservator mod de a face politică cu alte mijloace ${ }^{3}$, dacă este să ne raportăm la război în istoria umanităţii. Mai întâi, s-a renunţat la războiul liniar la nivel tactic, punându-se accent pe viteză, pe surprindere strategică, pe tehnologiile de tip stealth. Apoi, războiul s-a descentralizat prin asimetrie, prin ştergerea demarcaţiei dintre combatanţi și civili, prin dispariţia convenţiilor de purtare a războiului, care nu mai trebuie declarat, care transformă societatea în câmp de luptă, uniformele devenind opționale. Iar, în zilele noastre, asistăm cu surprindere că 
timpul „nu mai are răbdare” şi că ne aflăm deja în cea de-a cincea generaţie a războiului, în care hibridizarea şi acțiunile militare noncinetice, cum ar fi ingineria socială, dezinformarea, atacurile cibernetice, împreună cu tehnologiile emergente, de tip inteligența artificială și sistemele complet autonome, au surclasat acţiunile militare cinetice, transformând războiul într-o confruntare a informaţiei şi multiplicând teatrul de operaţii la nivelul tuturor sectoarelor societăţii.

Un câmp de luptă omniprezent, prefigurat la nivel conceptual de marele strateg prusac Carl Philipp Gottlieb von Clausewitz (1780-1831), teoreticianul războiului nelimitat (reteoretizat ulterior ca război absolutşirăzboitotal), al războiului fără spaţii neutre și necombatanţi, militarii şi civilii fiind angrenaţi în efortul comun de înfrângere completă a inamicului, până la victoria finală ${ }^{4}$. În zilele noastre, în acest câmp de luptă omniprezent acţionează un cumul de forță cineticăși preponderent noncinetică, violența militară convențională lăsând spaţiu de manevră violenţei politice, juridice, economice, informaţionale și tehnologice - după unii autori, chiar mai devastatoare decât un război convențional ${ }^{5}$. Idei teoretizate de doi colonei chinezi din Armata Populară de Eliberare, Qiao Liang şi Wang Xiangsui, care susţineau, în 1999, că războiul nelimitat din epoca modernă oferă naţiunilor defavorizate din punct de vedere militar şi politic şansa de a ataca cu succes o superputere geopolitică a cărei doctrină militară este condusă de tehnologie şi de efortul de a dezvolta noi şi noi clase de armament şi de vehicule, extrem de scumpe şi greu de integrat în sistemele deja existente. Observaţii împărtăşite şi de analiştii americani Frank G. Hoffman ${ }^{6}$ şi Nathan Freier ${ }^{7}$, sub forma conceptelor de război hibrid şi atacuri disruptive, sau de generalul rus Valeri Gherasimov, teoreticianul războiului nonliniar modern, care remarcă, într-un articol dedicat acestui subiect, că, „,indiferent de forțele pe care le are inamicul, oricât de bine dezvoltate ar fi forțele și mijloacele sale de conflict armat, pot fi găsite forme și metode pentru depășirea lor. El va avea întotdeauna vulnerabilităţi și asta înseamnă că există mijloace adecvate de a i se opune" 8 .

În aceeaşi ordine de idei, analistul american Harlan Ullman, teoretician al concepului de massive attack of disruption (MAD) - atac masiv perturbator -, consideră că războiul viitorului va fi unul al acestor atacuri disruptive, componente ale doctrinei shock and awe - şoc şi groază, prin care voinţa de luptă a adversarului este paralizată de anvergura copleşitoare a atacului. Aceste atacuri perturbatoare masive, descrise de Ullman ca fiind „cel de-al cincilea cavaler al Apocalipsei”, sunt produsul a şapte forţe perturbatoare principale: eşuarea guvernării, schimbările climatice, spaţiul cibernetic, reţelele de socializare, dronele, terorismul şi îndatorarea explozivă9. Forţe care vizează vulnerabilităţile societale, care acţionează sinergic prin potenţare reciprocă şi au impact masiv asupra populaţiei. Forţe care acţionează asupra „ţesăturii” de interese şi de dependenţe, create de interconexiunile societăţii globalizate, hipertehnologizate. Forţe care îngrozesc tocmai prin multitudinea de efecte, pe principiul dominoului, generate de interferenţa tehnologiei, de difuzia puterii şi destructurarea statelor westphaliene.

Idei în deplin acord cu conceptul de război nelimitat şi cu direcţia spre care se îndreaptă societatea hipertehnologizată a viitorului.

\section{Caracteristicile războiului de ultimă generaţie}

Există patru caracteristici majore ale războiului de a cincea generație:

- Rețelele digitale extinse, interconectate și interdependente, care asigură culegerea şi transmiterea de informații, detectarea, evaluarea impactului și transmiterea comenzii. Diferitele elemente de forță sunt noduri interacționale pe rețele care pot primi, acționa și transmite date. $\mathrm{Cu}$ cât aceste noduri sunt mai numeroase, cu atât puterea rețelei este mai mare, dacă este să ne raportăm la Legea matematică a lui Metcalfe, care afirmă că valoarea unei rețele de comunicații este proporțională cu pătratul numărului de utilizatori conectați la sistem ${ }^{10}$. Transmiterea datelor din teatrul de operaţii se face în timp real, prin sisteme de înregistrare video, încorporate în echipamentele militare aflate în acţiune.

- Combat cloud / Nor de luptă - reţelele pot forma un nor virtual de luptă - asemănător cu cloud computingul comercial - care permite extragerea și adăugarea de date prin activarea digitală a platformelor cheie de luptă - apărarea antirachetă, lupta aeriană, sistemele fără pilot, conectivitatea forței terestre cu alte categorii de forţe prin legături de date. 
- Luptă multidomeniu - la ora actuală, există cinci domenii operaționale sinergice: terestru, maritim, aerian, spațial și cibernetic.

- Războiul de fuziune - conceptul de război de fuziune descrie vulnerabilităţile generate de războiul de comandă şi control (cuprinde toate tacticile militare care utilizează tehnologia comunicațiilor), care decurg din fluxuri de informații suplimentare, incompatibilități software șivulnerabilități intrinseci la atac și înșelăciune ${ }^{11}$ - Operations security (OPSEC), Military deception, Psychological operations (PSYOP), Electronic warfare (EW), Psychological warfare, Cyber Operations.

\section{Impactul trecerii la războiul de generaţia a cincea}

Războiul modern atrage cu sine noi riscuri şi vulnerabilităţi, dar şi noi provocări, respectiv:

- vulnerabilitatea în faţa intruziunii cibernetice, care poate fura, șterge, modifica sau insera date false în sistem, date care se pot răspândi rapid în rețea, generând confuzie și denaturând informaţia;

- riscul detecţiei şi anihilării extinse prin arme ghidate cu precizie, în caz de compromitere a reţelei.

Prin urmare:

- securitatea cibernetică devine esențială, în contextul războiului modern, chestiune care este posibil să conducă la:

- crearea unei noi categorii de forţe, cyber, de sine stătătoare, având misiunea de a duce războiul cibernetic şi de a asigura securitatea cibernetică, contribuind fundamental la unificarea operaţională a tuturor categoriilor de forţe;

- dezvoltarea disciplinelor militare de profil şi a învăţământului de profil;

- apare nevoia fragmentării reţelelor mari în reţele mici şi independente, pe model neuronal, a căror eventuală compromitere ar genera pagube limitate. Dar, în acest caz, funcţionalitatea în cadrul sistemului este perturbată;

- cresc cheltuielile pentru cercetarea de vârf în domeniul cibernetic şi pentru achiziţia de echipamente de ultimă generaţie;

- reţelele aduc cu sine ideile de securitate colectivă şi de coaliţie. Dacă ar fi să luăm în calcul previziunile geopolitice, am putea afirma că războiul modern glisează spre componenta civilizațională, care atrage cu sine un număr mare de actori internaționali, uniţi prin interese, principii şi valori comune, imense teatre de operaţii, masive forţe angrenate în luptă, precum şi distrugeri şi costuri uriaşe ${ }^{12}$;

- tehnologia de vârf nu asigură, în mod obligatoriu, victoria. S-a demonstrat acest lucru în Vietnam şi Afganistan. Invazia, urmată de cucerire, se poate sfârşi printr-un eşec, dacă în joc intră componenta civilizațională, aspect spre care este posibil să ne îndreptăm în viitor.

Acestor aspecte se adăugă celelalte componente, noncinetice, ale războiului modern, care vizează aspectele subsumate conceptului de MAD, despre care s-a amintit deja în acest articol, la care s-ar putea include atacurile cu arma biologică împotriva oamenilor, şeptelului, pădurilor sau recoltelor.

Şi, nuînultimul rând, trebuie amintite cercetările din domeniul transumanismului, care urmăresc dezvoltarea unor tehnologii de îmbunătățire a biologiei umane, ca, de pildă, creșterea capacităţilor senzoriale, cognitive, psihologice, îmbunătățirea radicală a sănătătii umane și prelungirea duratei de viaţă a omului. Tehnologii care vor avea aplicaţii militare şi care vor aduce cu sine războiul de a şasea generaţie.

Ţinând cont de aceste aspecte, care, până de curând, au fost considerate ca aparţinând unui viitor îndepărtat, înţelegem de ce recenta confruntare din Transcaucazia a fost considerată un punct de inflexiune în domeniul militar.

\section{Scurte observaţii referitoare la cel de-al doilea război din Nagorno-Karabakh}

Până la împlinirea anticipărilor lui Ullman privind destructurarea actualului sistem internaţional, cel de-al doilea război din Nagorno-Karabakh a fost purtat în pură tradiţie westphaliană, între Armenia, prin autoproclamata Republică separatistă Artsakh, şi Azerbaijan, în perioada 27 septembrie 10 noiembrie 2020.

Nagorno-Karabakh este o zonă muntoasă enclavizată din Transcaucazia (Caucazul de Sud), în sud-vestul Azerbaidjanului, cu suprafaţa de aproximativ $4.400 \mathrm{~km}^{2}$. În urma războiului din 1994, prin ocuparea de către armeni a teritoriilor de deal şi câmpie din jurul regiunii, de la granita cu Iranul şi Armenia, dar şi din nord şi est, republica separatistă Artsakh ajunsese să controleze $8.223 \mathrm{~km}^{2} .^{13}$

Planul de război al Azerbaidjanului a urmărit ocuparea acestor regiuni joase, închiderea coridorului Lachin, care este singura conexiune rutieră între Nagorno-Karabakh și Armenia, 
izolarea și căderea Artsakh. Au fost lansate în luptă flota de vehicule aeriene fără pilot şi forța de rachete balistice tactice precise, care au distrus pozițiile fortificate şi echipamentele militare ale separatiştilor, astfel că, la cinci săptămâni de la debutul conflictului, trupele azere se aflau în preajma coridorului Lachin, iar în cea de-a şasea săptămână, forțele speciale azere au capturat orașul strategic Shusha, de unde au lansat atacuri cu mortiere asupra capitalei regiunii, Stepanakert. Ostilităţile s-au încheiat printr-un acord de încetare a focului şi victoria de facto a Azerbaidjanului, care a păstrat controlul asupra zonelor recucerite în Nagorno-Karabakh şi a obținut, de asemenea, comunicațiile de transport spre exclava sa din Nahicevan, învecinată cu Turcia și $\operatorname{Iran}^{15}$. La ora actuală, de-a lungul coridorului strategic Lachin dintre Armenia și Nagorno-Karabakh, au fost dispuse trupe ruseşti de menţinere a păcii (Figura 1).

În urma acestui nou episod de escaladare a conflictului îngheţat armeano-azer, separatiştii au pierdut peste 185 de tancuri (din totalul de 400 al pentru ca forțele terestre azere să se deplaseze şi să preia controlul unui punct strategic de constricție"17, precum afirmă analistul militar Uzi Rubin. Şi un război electronic, care a orbit radarele armene, facilitând astfel distrugerea lor şi a bateriilor de apărare antiaeriană, un război în care Erevanul a fost „out-fought, ouţ-numbered, and out-spent"18 - depăşit in luptă, depăşit numeric, depăşit în costuri. Un adevărat război postmodern, în care fiecare acţiune a fost filmată şi transmisă în timp real de către UAV-urile atacatoare.

Cât despre victorie, aceasta nu a fost deloc suprinzătoare, dacă este să luăm în calcul discrepanţa în privinţa puterii dintre cele două state, Azerbaidjanul fiind de trei ori mai mare, ca suprafață $^{19}$, de trei ori mai populat ${ }^{20}$, mai performant economic ${ }^{21}$ și mult mai bogat în resurse, îndeosebi energetice, decât Armenia.

O victorie însă extrem de surprinzătoare prin modul în care a fost obţinută.

Practic, războiul a fost câştigat din aer, şi nu la sol, unde înaintarea nu a fost în niciun caz una de tip

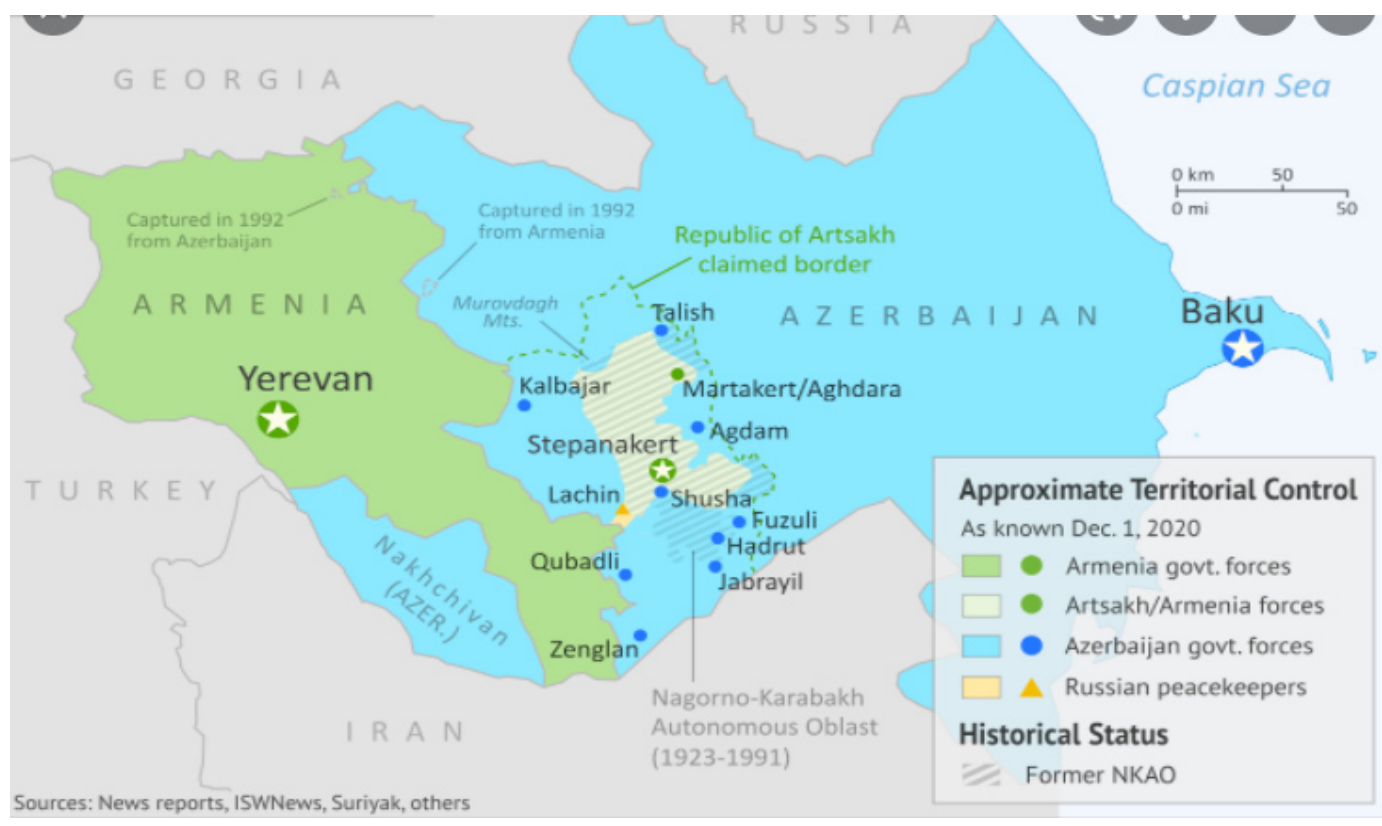

Figura 1 Harta politică a regiunii Nagorno-Karabakh la 1 decembrie $2020^{14}$

Armeniei), precum şi numeroase piese de artilerie, sisteme de apărare aeriană, lansatoare de rachete și vehicule de luptă ale infanteriei ${ }^{16}$. A fost primul război câștigat, în principal, de unmanned aerial vehicles - sistemele aeriene fără pilot (UAV). „Primul conflict postmodern [...] în care avioanele fără pilot au copleșit o forță terestră convențională, măcinând-o până la impotență și pavând o cale, blitz-krieg - război fulger ${ }^{22}$-, confirmând o teorie geopolitică apărută în spaţ̧iul public în anii '40, aparţinând unui militar şi om de afaceri american de origine georgiană, Alexander de Seversky (18941974), care spunea că strategia militară, definită ca fiind ,planul general care înfrânge geografia pentru a aplica forţa militară împotriva inamicului”, nu poate fi pe deplin aplicată în afara puterii aeriene, 
„expresia supremă a puterii militare”. Prin urmare, afirma Seversky, superioritatea aeriană reprezintă condiţia pentru a câştiga un război cu pierderi umane şi materiale puţine, întrucât ,vehiculele aeriene de astăzi, avioane sau rachete balistice conduse, deopotrivă, de mâna umană sau nu, se pot ridica direct din bazele lor naţionale şi pot lovi orice ţintă de pe glob [...] astăzi, forţa aerospaţială este singura forţă strategică şi este principalul instrument al puterii militare naţionale" ${ }^{23}$, pe cale de consecinţă, ţinta oricărei naţiuni care se doreşte victorioasă într-un război trebuind să fie ,dominaţia spaţiului aerian şi cosmic de deasupra sa" ${ }^{24}$. Sau, altfel spus, he who owns the skies, will own the ground-cel care controlează cerul va controla pământul.

Dominaţia aeriană, de data aceasta, nu a mai fost realizată convențional, prin avioane cu echipaj și elicoptere, vizibile pe radare şi vulnerabile în faţa unei apărări antiaeriene, ci printr-un foarte complex sistem de UAV-uri, care au asigurat supravegherea și localizarea efectivelor adverse (de tip real-time intelligence, surveillance and reconnaissance ISR), au indus în eroare apărarea armeană prin biplane vizibile pe radar, propulsate de elice şi echipate pentru pilotaj la distanţă, care au blocat radarele pe ţinte false, în timp ce au fost lansate atacuri cu bombe glisante din UAV-urile turceşti Bayraktar TB2 şi cu drone „sinucigaşe” HAROP de flotare, de provenienţă israeliană, care au distrus sisteme de apărare aeriană mobile, de proveniență rusească, de toate tipurile, de la vechiul $S A 8 O s a, S A 13$ Strela 10, până la modernul $S A 15$ Buk - sistemul de rachete care a doborât zborul 17 al Malaysian Airline peste estul Ucrainei, în 2014 - sau platforme de rachete sol-aer $S-300^{25}$.

În spatele acestei victorii, s-a aflat, în mod covârşitor, sistemul de război electronic Turkish $K O R A L$, proiectat să blocheze canalele de comunicații radar și wireless ${ }^{26}$, care a orbit radarele, făcând imposibilă detectarea dronelor turceşti şi israeliene.

Şi, mai trebuie amintit că nici Azerbaidjanul şi nici Armenia nu au folosit rachete balistice împotriva vreunei ţinte de pe teritoriile naţionale, din afara teatrului de conflict, din dorinţa de a nu escalada şi internaţionaliza războiul, cu toate că, în 17 iulie 2020, Azerbaidjanul a amenințat în mod deschis că va lovi centrala nucleară Metsamor din Armenia cu rachete balistice de precizie ${ }^{27}$.

\section{Impactul confruntării militare \\ din Transcaucazia asupra modului de ducere a războiului modern}

Confruntarea recentă din Nagorno-Karabakh a revoluţionat modul de ducere a războiului prin:

- demonstrarea vulnerabilităţilor armamentului convenţional în faţa celui de ultimă generaţie. Pe cale de consecinţă, menţinerea/achiziţionarea unor sisteme de armament învechite este total contraproductivă şi bugetivoră;

- nevoia unui sistem integrat de apărare aeriană (IADS) pentru a contracara amenințările aeriene moderne. Adică a combat cloud-ului aerian. $\mathrm{O}$ astfel de configurație, cu diferite straturi de capabilități moderne (cu rază lungă, medie, scurtă şi foarte scurtă de acţiune) şi bine conectate în rețea, ar permite mai bine gestionarea pletorei de provocări, de la avioanele tradiţionale şi radare, la roiuri de UAV;

- rolul fundamental al războiului electronic în războiul modern;

- reiterarea doctrinei tradiţionale, conform căreia superioritatea aeriană este o condiție prealabilă pentru câștigarea unui război terestru, dezvăluind o nouă modalitate mai eficientă din punctul de vedere al costurilor și mai nedureroasă de a-1 atinge prin dispariţia victimelor echipajelor aeriene;

- certificarea transformării radicale a câmpului de luptă în care operează deja sistemele fără pilot și ,vrăjitoriile” electronice;

- rolul fundamental al factorului uman, responsabil de planificarea strategică a apărării, şi al capacităţii unui stat de a-şi asigura economic apărarea într-un prezent dominat de un extrem de rapid avans tehnologic, care atrage după sine nevoia unui sistem de învăţământ militar flexibil, bazat pe creativitate, gândire analitică şi gândire strategică, adaptat noilor realităţi ale războiului;

- rolul fundamental al cercetării ştiinţifice în domeniul militar şi civil, care, în viitor, va face diferenţa dintre supravieţuire şi anihilare;

- importanta covârşitoare a alianţelor/ coaliţiilor, fără de care niciun stat nu va putea rezista în condiţiile „sprintului” tehnologic actual şi viitor.

Iar, ca o consecinţă imediată, în 2021 s-a înregistrat o creştere a cererii mondiale pentru UAV-uri armate și neînarmate şi pentru sisteme de război electronic ofensiv și defensiv. 
Mai trebuie amintit că succesul atacului cu drone a depins şi de starea vremii, care a permis o bună transmisie optică, aspect care aduce în discuţie armele tactice meteo şi rolul lor în contracararea unor atacuri cu UAV-uri.

Şi, nu în ultimul rând, trebuie amintit că actualele revoluţii industriale, aflate în spatele acestui avânt tehnologic, aduc cu sine noi materii prime - minereurile strategice - şi noi mize geopolitice, deci noi şi noi spaţii de confruntare şi o şi mai mare volatilitate a mediului internaţional.

Aceste aspecte confirmă faptul că războiul de a cincea generaţie este o certitudine care nu mai aparţine jocurilor de război şi anticipaţiei, rămânând doar o problemă de timp, deloc îndelungat, până când războiul va accede la următorul nivel, al celei de-a șasea generaţii, când roboţii androizi şi omul transhuman se vor confrunta în teatrele de operaţii.

Cât de pregătiţi vom fi atunci? Rămâne de văzut.

\section{NOTE:}

1 William S. Lind, Col. Keith Nightengale, Capt. John F. Schmitt, Col. Joseph W. Sutton, Lieutenant Colonel Gary I. Wilson, "The Changing Face of War: Into the Fourth Generation", Marine Corps Gazette, octombrie 1989.

2 Heidi Toffler, Alvin Toffler, War and Anti-War: Making Sense of Today's Global Chaos, Warner, Londra, 1993, passim.

3 Carl Philipp Gottlieb von Clausewitz, Despre război, Editura Antet, Bucureşti, 2001, passim.

4 Ibidem.

5 Qiao Liang, Wang Xiangsui, Unrestricted Warfare: China's Master Plan to Destroy America, People's Liberation Army Literature and Arts Publishing House, 1999, https://citeseerx.ist.psu.edu/viewdoc/summary?doi $=10.1 .1 .169 .7179$, accesat la 10.10.2021.

6 Frank G. Hoffman, "Hybrid Warfare and Challenges", Joint Force Quaterly (JFQ), Issue 52, First Quarter, 2009.

7 Nathan Freier, "Hybrid Threats and Challenges: Describe... Don't Define", Small Wars Journal, 06.01.2010, https://smallwarsjournal.com/jrnl/art/hybrid-threats-andchallenges-describe-dont-define, accesat la 10.10.2021.

8 "The «Gerasimov Doctrine» and Russian NonLinear War"Naleri Gherasimov, "The Value Of Science in Prediction", Military-Industrial Kurier, 27 februarie 2013, https://inmoscowsshadows.wordpress.com/2014/07/06/thegerasimov-doctrine-and-russian-non-linear-war/, accesat la 10.10.2021.

9 Harlan Ullman, Al cincilea cavaler al Apocalipsei și noul MAD, Editura Militară, Bucureşti, 2021, p. 30.

10 Peter Fisk, Metcalfe's Law explains how the value of networks grows exponentially ... exploring the "network effects" of businesses like Apple, Facebook, Trulia and Uber, 17.02.2020, https://www.peterfisk.com/2020/02/ metcalfes-law-explains-how-the-value-of-networks-growexponentially-there-are-5-types-of-network-effects/, accesat la 10.10.2021.

11 Peter Layton, Five fifth-generation warfare dilemmas, ASPI, 25.07.2017, https://www.aspistrategist.org.au/fivefifth-generation-warfare-dilemmas/, accesat la 10.10.2021.

12 Samuel P. Huntington, The Clash of Civilizations and the Remaking of World Order, Simon \& Schuster, 1996, passim.

$13^{* * *}$ Nagorno-Karabakh, World Atlas, https://www. worldatlas.com/geography/nagorno-karabakh.html, accesat la 10.10 .2021 .

14 https://1.bp.blogspot.com/-G3rnm9O235Q/X8ctv89 6HUI/AAAAAAAADTU/ a_J8SZKcE6Ub2GDnr_Qq4bE_ SvP8AzBbwCLcBGAsYHQ/s0/2020-12-01_azerbaijanarmenia-nagorno-karabakh-map-artsakh-after-withdrawals. png, accesat la 10.10.2021.

15 Andrew E. Kramer, "Facing Military Debacle, Armenia Accepts a Deal in Nagorno-Karabakh War", The New York Times, 10.11.2020, https://www.nytimes. com/2020/11/09/world/middleeast/armenia-settlementnagorno-karabakh-azerbaijan.html, accesat la 10.10.2021.

16 Uzi Rubin, The Second Nagorno-Karabakh War: A Milestone in Military Affairs, Begin-Sadat Center for Strategic Studies, Tel Aviv, 2020, p. 11, https://besacenter. org/wp-content/uploads/2020/12/184web-no-ital.pdf, accesat la 10.10.2021.

17 Uzi Rubin, op.cit. p., 5.

18 John Antal, The First War Won Primarily with Unmanned Systems: Ten Lessons from the Second NagornoKarabakh War, United States Special Operations Command, https://www.socom.mil/, accesat la 10.10.2021.

$1986.600 \mathrm{~km}^{2}$ - Azerbaidjan; $29.743 \mathrm{~km}^{2}$ - Armenia. ***CIA WorldFactBook, https://www.cia.gov/the-worldfactbook/countries/azerbaijan/; https:/www.cia.gov/theworld-factbook/countries/armenia/\#geography, accesat la 10.10.2021.

20 10.282.283 de locuitori - Azerbaidjan; 3.011.609 de locuitori - Armenia (estimare în iulie 2021). ${ }^{* * *} C I A$ WorldFactBook, https://www.cia.gov/the-world-factbook/ countries/azerbaijan/\#people-and-society; https://www.cia. gov/the-world-factbook/countries/armenia/\#people-andsociety, accesat la 10.10.2021.

21 PIB total (estimare în 2019): 144.374 de miliarde USD - Azerbaijan, 40.384 de miliarde USD - Armenia; PIB/ capita: 14.404 USD - Azerbaidjan, 13.654 USD - Armenia. ***CIA WorldFactBook, https://www.cia.gov/the-worldfactbook/countries/azerbaijan/\#economy; https://www. cia.gov/the-world-factbook/countries/armenia/\#economy, accesat la 10.10.2021.

22 Distanţa de la punctul atacului inițial la cel mai îndepărtat punct vestic este de aproximativ $100 \mathrm{~km}$ şi a fost parcursă în patru săptămâni. Distanța de la punctul atacului inițial la cel mai nordic punct este de aproximativ $80 \mathrm{~km}$ şi a fost parcursă în şase săptămâni. Uzi Rubin, op.cit., pp. 7-8.

23 Alexander de Seversky, Air Power: Key to Survival with a Prologue on the Lesson of Korea, Simon \& Schuster, New York, 1950, pp. 36-37, apud Alba Iulia Catrinel Popescu, Tratat de geopolitică, Volumul I: Geopolitica puterii maritime, Editura Top Form, Bucure;ti, 2020, pp. 164-165. 
24 Ibidem, p. 81, apud. Ibidem, p. 165.

25 Ben Ho, "The Second Nagorno-Karabakh War: Takeaways for Singapore's Ground-Based Air Defense", Journal of Indo-Pacific Affairs, Air University Press, 25.08.2021, https://www.airuniversity.af.edu/JIPA/Display/ Article/2743721/the-second-nagorno-karabakh-wartakeaways-for-singapores-ground-based-air-defen/, accesat la 10.10.2021.

$26 * * *$ Electronic warfare killed Russian-made weapons in Nagorno-Karabakh, Global Defense, 05.11.2020, https:// www.globaldefensecorp.com/2020/11/05/electronicwarfare/, accesat la 10.10.2021.

27 ***Azerbaijan Threatens Missile Strike On Armenia's Nuclear Power Plant, USC Dornsife Institute of Armenian Studies, 17.07.2020, https://armenian.usc.edu/azerbaijanthreatens-missile-strike-on-armenias-nuclear-power-plant/, accesat la 10.10.2021.

\section{BIBLIOGRAFIE}

*** Azerbaijan Threatens Missile Strike On Armenia's Nuclear Power Plant, USC Dornsife Institute of Armenian Studies, 17.07.2020, https:// armenian.usc.edu/azerbaijan-threatens-missilestrike-on-armenias-nuclear-power-plant/

*** CIA WorldFactBook

*** Electronic warfare killed Russian-made weapons in Nagorno-Karabakh, Global Defense, 05.11.2020, https:/www.globaldefensecorp.com/ 2020/11/05/electronic-warfare/

*** Nagorno-Karabakh, World Atlas, https:// www.worldatlas.com/geography/nagornokarabakh.html

Antal John, The First War Won Primarily with Unmanned Systems: Ten Lessons from the Second Nagorno-Karabakh War, United States Special Operations Command, https://www.socom.mil/

Von Clausewitz Carl Philipp Gottlieb, Despre război, Editura Antet, Bucureşti, 2001.

Fisk P., Metcalfe's Law explains how the value of networks grows exponentially ... exploring the "network effects" of businesses like Apple, Facebook, Trulia and Uber, 17.02.2020, https:// www.peterfisk.com/2020/02/metcalfes-lawexplains-how-the-value-of-networks-grow-expone ntially-there-are-5-types-of-network-effects/

Freier Nathan,"Hybrid Threats and Challenges: Describe... Don't Define", Small Wars Journal, 06.01.2010, https://smallwarsjournal.com/jrnl/art/ hybrid-threats-and-challenges-describe-dontdefine

Gherasimov Valeri, "The Value Of Science in Prediction", Military-Industrial Kurier,
27 Februarie 2013, https://inmoscowsshadows. wordpress.com $/ 2014 / 07 / 06 /$ the-gerasimovdoctrine-and-russian-non-linear-war/

Ho Ben, "The Second Nagorno-Karabakh War: Takeaways for Singapore's Ground-Based Air Defense", Journal of Indo-Pacific Affairs, Air University Press, 25.08.2021, https://www. airuniversity.af.edu/JIPA/Display/Article/2743721/ the-second-nagorno-karabakh-war-takeaways-forsingapores-ground-based-air-defen/

Hoffman Frank G., "Hybrid Warfare and Challenges", Joint Force Quaterly (JFQ), Issue 52, First Quarter, 2009.

Huntington Samuel P., The Clash of Civilizations and the Remaking of World Order, Simon \& Schuster, 1996.

Kramer Andrew E., "Facing Military Debacle, Armenia Accepts a Deal în Nagorno-Karabakh War", The New York Times, 10.11.2020, https:// www.nytimes.com/2020/11/09/world/middleeast/ armenia-settlement-nagorno-karabakh-azerbaijan. html

Layton Peter, Five fifth-generation warfare dilemmas, ASPI, 25.07.2017, https://www. aspistrategist.org.au/five-fifth-generation-warfaredilemmas/

Lind William S., Col. Nightengale Keith, Capt. Schmitt John F., Col. Sutton Joseph W., Lt.Col. Wilson I. Gary, "The Changing Face of War: Into the Fourth Generation", Marine Corps Gazette, octombrie 1989.

Liang Qiao, Xiangsui Wang, Unrestricted Warfare: China's Master Plan to Destroy America, People's Liberation Army Literature and Arts Publishing House, 1999, https://citeseerx.ist.psu. edu/viewdoc/summary?doi=10.1.1.169.7179.

Popescu Alba-Iulia Catrinel, Tratat de geopolitică, Volumul I: Geopolitica puterii maritime, Editura Top Form, Bucureşti, 2020.

Rubin Uzi, The Second Nagorno-Karabakh War: A Milestone in Military Affairs, BeginSadat Center for Strategic Studies, Tel Aviv, 2020, https://besacenter.org/wp-content/uploads/ 2020/12/184web-no-ital.pdf

Toffler Alvin, Toffler Heidi, War and Anti-War: Making Sense of Today's Global Chaos, Warner, Londra, 1993.

Ullman Harlan, Al cincilea cavaler al Apocalipsei şi noul MAD, Editura Militară, Bucureşti, 2021. 